\title{
When cancer wakes up ghosts of the past
}

\begin{abstract}
Cancer diagnosis may be considered as a psychosomatic crisis and the disease can be perceived as a part of himself that inexplicably turns into a destructive and mortal nonself. Then the deep psychosomatic crisis linked to cancer is able to produce a process of regression and disorganization of previous defensive structures. Often, memories of particularly traumatic events can be reactivated by successive traumatic experiences at sensory level. WE present the case of a 10years-old boy, hospitalized at the Department of Hematology suffering from leukemia, who presented an epileptic episode we suspected of psychogenic nature (by conversion). The story revealed a sexual abuse when he was six years old. The analysis of test showed a pre-genital functioning registry, the need for cohesion and inner stability in a boy that, in contrast, feels a lived experience of inner inconsistency and lability. A possible outcome due to poor development of the psychological Self, with consequent separation conflict, is that the body can be used to hold and act mental states, assuming the function of meta-representation of feelings, ideas and wishes.

A good communication is essential to create a therapeutic alliance with the patient. However, it is insufficient and confusing if not based on a deep understanding of the fantasies and emotions with the burden of biological experience with unconscious meanings related to early experiences. Without considering these aspects, communicative distortions may jeopardize the therapeutic alliance, interfering with the process of coping. Working through regression in the areas of the unconscious meanings, allows the patient to understand the significance of his illness instead of exorcising it. This helps the patient to re-establish communication between the mind paralyzed by somatic events and the sick body that needs treatment.
\end{abstract}

Keywords: trauma, cancer,conversion disorder, mentalizing
Volume 4 Issue 2 - 2015

Francesca Riccardi, Daniela Caprino

Department of Pediatric Hematology and Oncology, G Gaslini

Scientific Children's Hospital, Italy

\begin{abstract}
Correspondence: Daniela Caprino, Department of Pediatric Hematology and Oncology, G Gaslini Research Children's Hospital, Largo Gerolamo Gaslini 5, I6I47 Genova, Italy, Email danielacaprino@ospedale-gaslini.ge.it
\end{abstract}

Received: October 15, 2015 | Published: November 16, 2015

\section{Introduction}

The onset of illness may be considered as a psychosomatic crisis due to changes in the role of personal and social regression and dependency, and then to a mental suffering. The tumor is perceived as a part of himself that inexplicably turns into a destructive and mortal non-self, it evokes fantasies of transformation, creating an anguished confusion between illness and sick person, between victim and persecutor. The deep psychosomatic crisis linked to cancer is able to produce a process of regression and disorganization of previous defensive structures. It is important to act before the crisis organizes itself in a psychologically disabling form, using the new trigger (their cancer) to start a new process of development.

Often, memories of particularly traumatic events can be reactivated by successive traumatic experiences at sensory level: "the body keeps the score". ${ }^{1}$ This could be linked to brain and psychological systems encoding and organizing the explicit memory that can be bypassed by uncontrollable emotional input trauma-related. Therefore the memories of the exposure to these stimuli are less integrated at sensory levels than the memories mediated by autobiographical and verbal memory. 2,3

Sensory memory generally lacks autobiographical material and it is often experienced as an intrusion of unexpected sensations. Although the sensory reactivation is often accompanied by emotions associated with the time of injury, the sensory memory of the experience of trauma and suffering may be a separate phenomenon. 4,5 In many cases, the sensory memory is the stimulus that may lead to traumatic reactivation. From a phenomenological point of view, when the trauma occurred, the mind comes unstuck from the body and the body comes off the ambient. After all, the mind development is a step- by-step process that goes from the body to the mind and flows into body self. ${ }^{6}$

The rational and verbal communication is essential to create a therapeutic alliance with the patient. However, it is insufficient and confusing if not based on a deep understanding of the fantasies and emotions, that are active in the regressive phase, with the burden of biological experience with unconscious meanings related to early experiences and in general to the personal story. Without an understanding of these aspects, communicative distortions may jeopardize the therapeutic alliance, interfering with the process of coping. If the repressed psychic experiences are integrated, the psychic development that was fixed, can retake.

\section{Case presentation}

Tom is a 10years-old boy, hospitalized at the Department of Hematology suffering from leukemia. The child showed during the early contacts the recourse to intellectualization mechanism and low frustration tolerance. The child continuously asks for going back home. He showed anxiety symptoms, as somatization of affection that made necessary a psychological evaluation. A week after the evaluation Tom presents an epileptic episode, with apnea, failure to respond to painful stimuli, however without loss of consciousness and urine. When the crises resolved tremors and the memory of what happened persisted, Tom turned on his side and got into fetal position. These crises were monitored and several tests were performed in order to understand the nature of the events. The psychological assessment consisted of two projective tests: Children Apperception Test (CAT) and Rorschach Test.

Based on the results of the analysis and tests, we suspected a psychogenic nature (by conversion) of the crises. ${ }^{7}$ The father informed 
about the possibility of the psychological origin of the disorder was distraught by the news, exclaiming: "We take care of the leukemia, but we fried the brain of this poor child "; "Dr. believe me: Leukemia is now the last problem for us."

The mother, however, does not seem particularly surprised but as it seems that there is still some "unspoken" instance, I have asked to speak to her alone. In that circumstance she told me that when Tom was 6years old, during a period of holiday at the seaside with his parents, he has been forced by a peer (eleven years old) to have oral sex. The mother realized that there was something wrong because the child begun to wet his bed. The mother then asked the boy why he had started wetting his bed and if there was any problem. Tom told her what happened during that holiday at the seaside and explained that he did it to go away as soon as possible. She was upset because Tom did not refuse to perform such a request. The mother asked for help from a psychologist she knows, whose response was not to pay particular attention to the event, because it was just a game between children.

\section{Discussion}

Based on the analysis of these protocols, it is evident a pregenital functioning registry where emerges the need for cohesion and inner stability in a boy that, in contrast, feels a lived experience of inner inconsistency and lability. The main conflict would seem to be connected with an archaic-omnipotent maternal representation saturated with aggressiveness, we can speculate that aroused from the difficulty in "handling" the early exchanges mother-father/child. Therefore, it emerges the issue of abandonment and frustration and the need of protection, in which the research of a support is either self-managed or moved on objects-things in an effort to find a support in the external reality.

The functioning appears oriented towards aspects of inhibition and control that are included into a narcissistic register with dysphonic aspects. However, when strong pulses arise, they disrupt the ability to process the thought of the person who undergoes to a real block of the capability of metalizing. The representation of parental imago is not sufficiently responsive to the emotional needs of the subject. Such failure would refer to the difficulty in the function of parental reverie $e^{8}$ and to the consequent absence of psychic third dimension, which could lead to act mental events. ${ }^{9}$ Turning on fetal position means an attachment recall to the parental figures, acted to get help.

In fact, Tom shows a general avoidance of mental states that could reduce the ability to identify and establish links with an intimate inclusive object. Another possible outcome due to poor development of the psychological Self, with consequent separation conflict, is that the body can be used to hold and act mental states, assuming the function of meta-representation of feelings, ideas and wishes..$^{10}$ Moreover, Tom does not appear able to access to the oedipal triangulation, mainly due to the phobic component associated with that stage of development. This data, combined with observations from the Rorschach test, would lead to a sexual problem that the subject appears unable to solve and process.

The occasional efforts to maintain a safe perception, the research and the need of support can be a favorable prognostic index for psychotherapy, aimed at enabling better integration of identity and a more adequate management of emotions and affections, trying to solve the trauma. Working through regression in the areas of the unconscious meanings, allows the patient to understand the significance of his illness instead of exorcising it. This helps the patient to re-establish communication between the mind paralyzed by somatic events and the sick body that needs treatment. In an effort to verbalize and translate the experience, we should not forget that the patient arrives with a previous history, and particular attention should be given to those fantasies that are associated with the problematic nuclei, denied or rationalized, on which you intend to work on. When the patient has experienced a previous trauma, the therapist must assess how the psychic apparatus of the patient may face the current traumatic process, taking into account all the components.

The traumatic reaction urges the subjects at regressed positions and to construct their own theory and story about their experience. However, this defense mechanism can result too rigid to lead to a good coping process. The more a child is in a state of hyper arousal or dissociation, the more likely they are to have neuropsychiatric symptoms following trauma. The therapeutic attention will be focused on metalizing, ${ }^{11}$ identifying and investigating emotions, working with current mental states. The therapeutic work should integrate the body story with the language to create a shared significance through the narrative of explicit Self and implicit Self. ${ }^{12,13}$

\section{Acknowledgments}

None.

\section{Conflicts of interest}

Author declares there are no conflicts of interest.

\section{Funding}

None.

\section{References}

1. Van der Kolk BA. The body keeps the score: Memory and the evolving psychology of post-traumatic stress. Harvard Rev Psychiat . 1994;1(5):253-265.

2. Van der Kolk BA. The complexity of adaptation to trauma: Selfregulation, stimulus discrimination, and characterological development. In: Van der Kolk BA, et al. (Eds.), Traumatic Stress: The effect of overwhelming experience on mind, body, and society. (1st edn), Guilford Press, New York, USA. 1996. p.182-213.

3. Siegel . Toward an interpersonal neurobiology of the developing mind: attachment relationships, "mindsight," and neural integration. Infant Mental Health Journal . 2001;22(1-2):67-94.

4. Davis M. The role of amygdala in fear and anxiety. Annu Rev Neurosci . 1992;15:353-375.

5. LeDoux JE. Emotion: Clues from the Brain. Annu Rev Psychol. 1995;46:209-235.

6. Mahler MS, McDevitt JB. Thoughts on the emergence of the sense of self, with particular emphasis on the body self. J Am Psychoanal Assoc. 1982;30(4):827-848.

7. American Psychiatric Association. Diagnostic and statistical manual of mental disorders. (5th edn), American Psychiatric Publishing, Washington, DC, USA. 2013.

8. Bion WR. A theory of thinking. Int J Psychoanal. 1962; 4.

9. Meltzer D. Dimensionality in mental functioning. In: D Meltzer, et al. (Eds.), Explorations in Autism: A Psychoanalytical Study. (3rd edn), Clunie Press, Perthshire, Scotland. 1975. p.223-238.

10. Fonagy P, Target M. Understanding the violent patient: The use of the body and the role of the father. International Journal of PsychoAnalysis. 1995;76:487-501. 
11. Bateman AW, Fonagy P. Psychotherapy for borderline personality disorder: Mentalization-based treatment. (1st edn), Oxford University Press, New York, USA. 2004.

12. Ogden TH, Pain C, Minton K, et al. Including the body in mainstream psychotherapy for traumatized individuals. Psychologist-Psychoanalist $X X V$. 2006;(4):19-24
13. Schore AN. The Right Brain Implicit Self: a central mechanism of the psychotherapy change process. In: J Petrucelli (Ed.), Knowing, NotKnowing and Sort-of-Knowing: Psychoanalysis and the Experience of Uncertainty. (1st edn), Karnac Books, London. 2010. p.177-202. 